University of Nebraska - Lincoln

DigitalCommons@University of Nebraska - Lincoln

Mechanical \& Materials Engineering Faculty

Publications

Mechanical \& Materials Engineering,

Department of

\title{
$4-26-2019$
}

\section{Influence of Metal Additives on Microstructure and Properties of Amorphous Metal-SiOC Composites}

\author{
Kaisheng Ming \\ University of Nebraska-Lincoln, ming@unl.edu \\ Qing Su \\ University of Nebraska-Lincoln, qsu3@unl.edu \\ Chao Gu \\ South University of Science and Technology, Shenzhen \\ Dongyue Xie \\ University of Nebraska-Lincoln, dxie5@unl.edu \\ Yongqiang Wang \\ Los Alamos National Laboratory, yqwang@lanl.gov
}

See next page for additional authors

Follow this and additional works at: https://digitalcommons.unl.edu/mechengfacpub

Part of the Mechanics of Materials Commons, Nanoscience and Nanotechnology Commons, Other Engineering Science and Materials Commons, and the Other Mechanical Engineering Commons

Ming, Kaisheng; Su, Qing; Gu, Chao; Xie, Dongyue; Wang, Yongqiang; Nastasi, Michael; and Wang, Jian, "Influence of Metal Additives on Microstructure and Properties of Amorphous Metal-SiOC Composites" (2019). Mechanical \& Materials Engineering Faculty Publications. 386.

https://digitalcommons.unl.edu/mechengfacpub/386

This Article is brought to you for free and open access by the Mechanical \& Materials Engineering, Department of at DigitalCommons@University of Nebraska - Lincoln. It has been accepted for inclusion in Mechanical \& Materials Engineering Faculty Publications by an authorized administrator of DigitalCommons@University of Nebraska Lincoln. 
Authors

Kaisheng Ming, Qing Su, Chao Gu, Dongyue Xie, Yongqiang Wang, Michael Nastasi, and Jian Wang 


\title{
Influence of Metal Additives on Microstructure and Properties of Amorphous Metal-SiOC Composites
}

\author{
Kaisheng Ming, ${ }^{1,2}$ Qing Su, ${ }^{1}$ Chao Gu, ${ }^{1,3}$ Dongyue Xie, ${ }^{1}$ \\ Yongqiang Wang, ${ }^{4}$ Michael Nastasi, ${ }^{1,5}$ \& Jian Wang ${ }^{1,5}$
}

1 Mechanical and Materials Engineering, University of Nebraska-Lincoln, Lincoln, NE 68588, USA

2 Key Laboratory of Aerospace Materials and Performance (Ministry of Education), School of Materials Science and Engineering, Beihang University, Beijing 100191, People's Republic of China

3 Department of Physics, South University of Science and Technology, Shenzhen 518055, People's Republic of China

4 MST Division, Los Alamos National Laboratory, Los Alamos, NM 87544, USA

5 Nebraska Center for Materials and Nanoscience, University of NebraskaLincoln, Lincoln, NE 68588, USA

Corresponding author — Jian Wang, email jianwang@unl.edu

\begin{abstract}
Strong, ductile, and irradiation-tolerant structural materials are in urgent demand for improving the safety and efficiency of advanced nuclear reactors. Amorphous ceramics could be promising candidates for high irradiation tolerance due to thermal stability and lack of crystal defects. However, they are very brittle due to plastic flow instability. Here, we realized enhanced plasticity of amorphous ceramics through compositional and microstructural engineering. Two metal-amorphous ceramic composites, Fe-SiOC and $\mathrm{Cu}-\mathrm{SiOC}$, were fabricated by magnetron sputtering. Iron atoms are preferred to form uniformly distributed nano-sized Fe-rich

Published in JOM 2019

doi 10.1007/s11837-019-03484-x

Copyright (c) 2019 The Minerals, Metals \& Materials Society; published by Springer Nature. Used by permission.

Published 26 April 2019.
\end{abstract}


amorphous clusters, while copper atoms grow non-uniformly distributed nanocrystalline $\mathrm{Cu}$ particles. The Fe-SiOC composite exhibits high strength and plasticity associated with strain hardening, as well as a good thermal stability and irradiation tolerance. In contrast, the $\mathrm{Cu}-\mathrm{SiOC}$ composite displays a very low plasticity and poor thermal stability. These findings suggest that the metal constituents play a crucial role in developing microstructure and determining properties of metalamorphous composites.

\section{Introduction}

To meet the rapidly increasing demands for future nuclear energy, strong, ductile, and irradiation- tolerant core structural materials are in urgent demand for improving the safety and efficiency of advanced nuclear reactors. ${ }^{1-4}$ Polycrystalline materials such as austenitic steels have great potential for use in fast reactors but could not reliably serve beyond $\sim 150$ displacements per atom (dpa). ${ }^{5,6}$ Ferritic and ferritic-martensitic (FM) steels have been found to swell much less than austenitic steels. ${ }^{7}$ Nanostructuring of both austenitic and FM steels appears to be a promising avenue for further improvement of swelling resistance, providing that such structures are stable under irradiation. ${ }^{8}$ Advanced oxide dispersionstrengthened alloys were found to be a promising core structural material, but amorphization and dissolution of oxide particles under high dpa irradiation challenges potential applications. ${ }^{9-11}$ Interfaces (interphase boundaries and grain boundaries) between the metal matrix and nanoscale oxides in oxide dispersion- strengthened steel systems prove to benefit swelling resistance and creep resistance. ${ }^{12}$ Interfaces in nanoscale materials have shown strong defect sink strength and the ability to suppress He bubble formation. ${ }^{13,14}$ However, all of these do not change the intrinsic issue - radiation-induced damage in crystalline materials.

In contrast to crystalline materials, amorphous materials could be very promising candidates for high radiation tolerance since they do not contain conventional crystal defects, such as vacancies, interstitials, or dislocations which evolve in crystalline materials under irradiation. Recent studies indicate that amorphous silicon oxycarbide (SiOC) ceramic displays excellent irradiation tolerance, thermal stability and mechanical properties. ${ }^{15-19}$ For instance, amorphous SiOC ceramics can retain their amorphous structure without crystallization, void formation or segregation under ion irradiation doses up to $50 \mathrm{dpa}$ at temperatures up to $600^{\circ} \mathrm{C} \cdot{ }^{15,18,20-22} \mathrm{Amorphous} \mathrm{SiOC}$ has also been shown to have a high crystallization temperature (over $1300^{\circ} \mathrm{C}$ ), good oxidation and creep resistance. ${ }^{23-28}$ 
Amorphous ceramics, however, exhibit 'brittle-like' behavior due to plastic flow instability, though they in general exhibit superior thermomechanical properties with respect to strength and hardness, creep and oxidation resistance, and structural stability at high temperatures and irradiation. Experimental and modeling studies have revealed that amorphous materials plastically deform via shear transformation zones at small deformation and shear banding at large deformation. ${ }^{29-35}$ The shear transformation zones mechanism is connected to microstructural heterogeneities (i.e., statistical heterogeneities such as statistically distributed free volume) in amorphous material. The shear instability associated with formation and propagation of shear bands is ascribed to statistically occurring, spatially homogeneous nucleation of shear transformation zones and their coalescence. . $^{30,31,36,37}$

Improving the plasticity of amorphous materials can be realized through composition engineering and microstructural engineering. ${ }^{38}$ However, composition engineering does not change the intrinsic issue of amorphous materials, i.e., shear banding, though their plasticity can be improved to some extent. In contrast to composition engineering, microstructural engineering shows more promise for tailoring the mechanical properties of amorphous materials. Crystalline/amorphous and amorphous/ amorphous multilayers may exhibit either uniform deformation or flow localized in discrete shear bands, depending on the thickness of individual layers and the type of interfaces between the layers. ${ }^{39-41}$ In addition to laminar microstructure, another approach to preventing flow localization is to combine phases with distinct flow localization behavior in a single composite with crystalline/amorphous phases, ${ }^{42,43}$ or gradient or bimodal microstructures. ${ }^{44-47}$ When deformed, such composites develop limited regions of flow localization. However, the alternation of flow localizing and uniformly deforming phases in the composite impedes individual flow-localized zones from extending across the entire length of the material.

In the present work, we synthesized metal-SiOC composites using co-sputtering techniques which couple microstructure engineering with composition engineering. Microstructural characterization revealed the formation of metal-rich nanosized clusters in amorphous SiOC. Two metal elements, Fe and $\mathrm{Cu}$, were selected to investigate the distribution and phase structure of the metal-rich nanosized clusters in the SiOC amorphous matrix, and their corresponding influence on thermal stability and mechanical properties. Fe-SiOC composites, with uniformly distributed nano-sized Fe-rich amorphous clusters, exhibited high strength and plasticity and corresponding strain hardening, as well as a good thermal 
stability, while Cu-SiOC composites, with non-uniformly distributed nanocrystalline Cu particles, exhibited brittle behavior and poor thermal stability. In addition, the Fe-SiOC composite also displayed a good irradiation tolerance.

\section{Experimental Procedures}

Amorphous SiOC films were synthesized through radio frequency (RF) co-sputtering $\mathrm{SiO}_{2}$ and $\mathrm{SiC}$ targets by magnetron sputtering techniques at room temperature onto $\mathrm{Si}$ substrates with a $300-\mathrm{nm} \mathrm{SiO}_{2}$ surface layer. The Fe-SiOC and Cu-SiOC composites were fabricated by the co-deposition of pure $\mathrm{Fe}$ and $\mathrm{Cu}$, respectively, which can result in the synthesis of an amorphous SiOC ceramic containing Fe/Cu solute atoms because of the low deposition temperature. The content of Fe or $\mathrm{Cu}$ is controlled by tilting the Fe or Cu gun towards or away from the substrate. Here, we fabricated a Fe-SiOC film with the Fe content of 22 at.\%, and a Cu-SiOC film with the Cu content of 21 at.\%, which were measured by Rutherford backscatter spectroscopy. The thickness of the as-deposited films was approximately $5 \mu \mathrm{m}$. A portion of the as-deposited Fe-SiOC and $\mathrm{Cu}-\mathrm{SiOC}$ composite films were then annealed at $800^{\circ} \mathrm{C}$ for $1 \mathrm{~h}$ in vacuum. In addition, a portion of the as-deposited Fe-SiOC composite films were subjected to Cu ion irradiation to damage levels of $0.5 \mathrm{dpa}$ at room temperature. Based on the Stopping and Range of lons in Matter calculation, we conducted a series of $\mathrm{Cu}$ ion irradiations of different energies ( $1 \mathrm{MeV}$, $2 \mathrm{MeV}, 3 \mathrm{MeV}, 4 \mathrm{MeV}, 5 \mathrm{MeV}$ ) which generated a nearly uniform distribution of damage throughout the top 3- $\mu \mathrm{m}$ films, and the maximum amount of implanted $\mathrm{Cu}$ in the irradiated layer was estimated to be less than 0.02 at.\%.

The microstructures of the SiOC, Fe-SiOC, and Cu-SiOC films were analyzed using multiple techniques. Cross-sectional and plan-view specimens were prepared for observation by transmission electron microscopy (TEM) (A FEI Tecnai G2 F20) and scanning electron microscope (SEM) coupled with energy dispersive spectroscopy (EDS). Specimens for TEM observation were made by grinding and polishing followed by low-energy (3.5 keV) ion-milling. The micro-pillars with diameters of around 2 $\mu \mathrm{m}$ were fabricated from films by using focused ion beam methods. The height-to-diameter ratio of each pillar was around 2-3. In situ SEM microcompression tests were performed on the micropillars at room temperature using a PI85 Picolndenter (from Hysitron) with a flat punch diamond 
tip under displacement-control mode at a loading rate of $5 \mathrm{~nm} / \mathrm{s}$. Three pillars for each material were subjected to micro-compression tests to confirm reproducibility.

\section{Results and Discussion}

Figure 1a shows the typical cross-sectional TEM bright-field (BF) image of the as-deposited amorphous SiOC film. Clearly, many nano-scale voids distributed along the growth direction of the SiOC film are formed during sputtering. The selected-area electron diffraction (SAED) pattern inserted in Fig. 1a distinctly displays the typical amorphous halo, implying
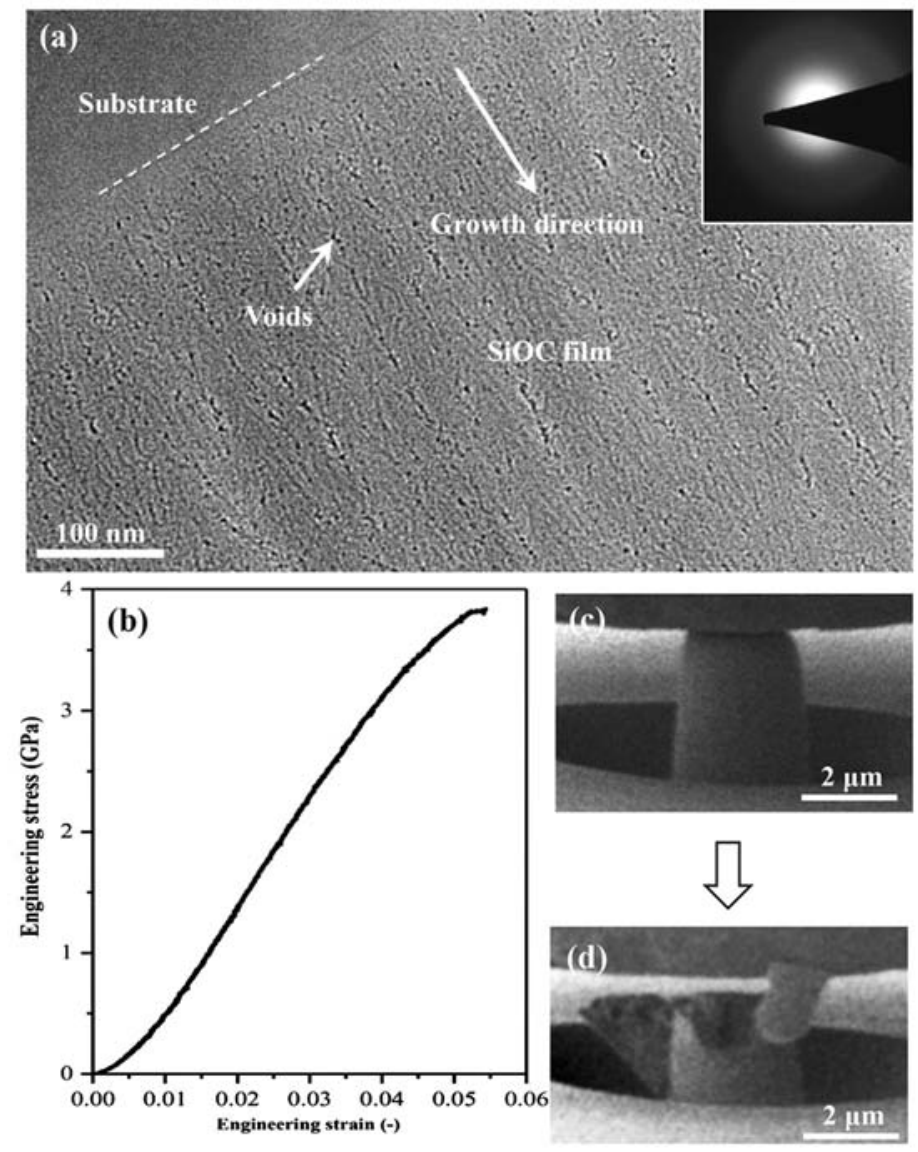

Fig. 1. Microstructures and mechanical properties of the as-deposited amorphous SiOC film. (a) Cross-sectional TEM micrograph of the SiOC, with the corresponding SAED pattern inset. (b) Room-temperature engineering stress-strain curve of the micro-pillar fabricated from SiOC film. SEM images of the micro-pillar (c) before and (d) after compression tests. 
the amorphous structure of the SiOC film. Figure $1 \mathrm{~b}$ shows the representative room-temperature engineering stress-strain curve of the micropillars fabricated from the as-deposited amorphous SiOC film. Figure $1 \mathrm{c}$ and $d$ shows the corresponding SEM images of the micro-pillar before and after micro-compression test, respectively. The as-deposited SiOC pillar exhibited catastrophic brittle fracture under compression. The poor plasticity can be attributed to the formation of numerous voids due to shadowing effects during film deposition. ${ }^{48}$

In order to eliminate the voids and introduce metal solute atoms in the amorphous SiOC film, we co-sputtered $\mathrm{Fe}$ or $\mathrm{Cu}$, which due to their high diffusivity resulted in relatively void-free amorphous SiOC. Figure 2 shows the typical cross-sectional TEM BF, scanning TEM (STEM) and high-resolution TEM (HRTEM) images of the two amorphous SiOC films containing 22 at.\% of Fe (Fig. $2 a_{1}, a_{2^{\prime}}$ and $a_{3}$ ) and 21 at.\% of $\mathrm{Cu}$ (Fig. $2 \mathrm{~b}_{1^{\prime}}$ $b_{2^{\prime}}$ and $b_{3}$ ), respectively. The voids are successfully removed in both films.
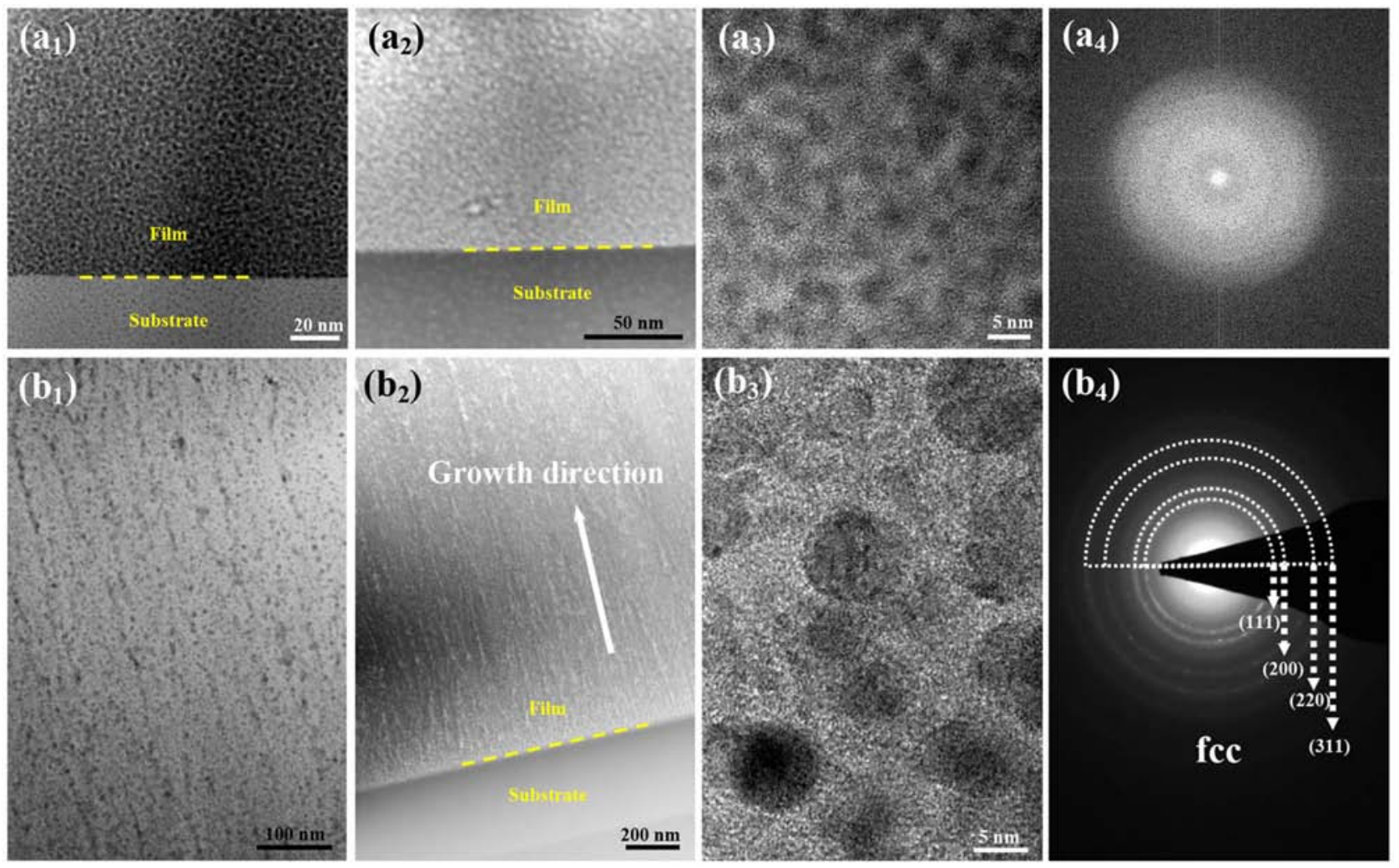

Fig. 2. Microstructure characterization of the as-deposited $\left(\mathbf{a}_{1}-\mathbf{a}_{4}\right) \mathrm{Fe}-\mathrm{SiOC}$ and $\left(\mathbf{b}_{\mathbf{1}}-\right.$ $\mathbf{b}_{\mathbf{4}}$ ) Cu-SiOC films using multiple techniques. $\left(\mathbf{a}_{\mathbf{1}}, \mathbf{b}_{\mathbf{1}}\right)$ TEM BF image; $\left(\mathbf{a}_{\mathbf{2}}, \mathbf{b}_{\mathbf{2}}\right)$ STEM images; $\left(\mathbf{a}_{\mathbf{3}}, \mathbf{b}_{\mathbf{3}}\right)$ HRTEM images; and $\left(\mathbf{a}_{\mathbf{4}}, \mathbf{b}_{\mathbf{4}}\right)$ FFT/SAED patterns. 
The Fe-SiOC and $\mathrm{Cu}-\mathrm{SiOC}$ composites exhibited quite different microstructures. The STEM and HRTEM characterizations of the Fe- SiOC composite demonstrated the formation of uniformly distributed nano-sized Fe-rich clusters in the amorphous ceramic matrix (Fig. $2 \mathrm{a}_{2}$ and $\mathrm{a}_{3}$ ). The corresponding fast Fourier transform (FFT) pattern in Fig. $2 \mathrm{a}_{4}$ distinctly shows the amorphous halo, indicating that no crystalline phases form in the composite amorphous ceramic. In contrast, for the $\mathrm{Cu}-\mathrm{SiOC}$ composite, large numbers of crystalline $\mathrm{Cu}$ nano-particles are non-uniformly distributed in the amorphous ceramic matrix, exhibiting a columnar distribution along the growth direction of the film, as evidenced in Fig. $2 b_{1}$, $b_{2}$, and $b_{3}$. Figure $2 b_{4}$ presents the ring diffraction pattern from the $\mathrm{Cu}$ nano-particles, showing a face-centered cubic crystal structure. During sputtering, Fe and $\mathrm{Cu}$ atom segregation occurs in the amorphous SiOC ceramic, filling the voids accompanied by nano-sized Fe-rich clusters and crystalline $\mathrm{Cu}$ nano-particles, respectively, in order to reduce the chemical potential compared to a homogeneous distribution of individual metal solute atoms.

Figure $3 a$ and $b$ shows the top-view and a cross-section view (inserted at the top-right) SEM (or STEM inset in Fig. 3a) images of the FeSiOC and Cu-SiOC composites after vacuum annealing at $800^{\circ} \mathrm{C}$ for $1 \mathrm{~h}$, respectively. There are no microstructure changes in the annealed FeSiOC composite, where Fe atoms remain in the amorphous matrix (Fig. 3a), indicating the composite's good thermal stability. In contrast, Cu atoms in the Cu-SiOC composite diffuse to the surface of the film, leading to the formation of numerous micro-sized $\mathrm{Cu}$ particles and nanowires (Fig. 3b). As shown in the cross-sectional view SEM image inserted at the top-right of Fig. 3b, column boundaries may provide a diffusion channel for $\mathrm{Cu}$ atoms during the annealing process. The photograph inserted at the lower-left of Fig. 3b shows the $\mathrm{Cu}-\mathrm{SiOC}$ sample before and after annealing, confirming the presence of $\mathrm{Cu}$ at the surface of the annealed film. The SEM-EDS mapping images in Fig. 3c-f further confirm the formation of $\mathrm{Cu}$ particles and nanowires at the surface of the annealed $\mathrm{Cu}$-SiOC composite, where both the particles and nanowires are enriched in $\mathrm{Cu}$ but poor in $\mathrm{Si}$ and $\mathrm{O}$. The annealing-induced $\mathrm{Cu}$ diffusion from the amorphous matrix to the free surface can be explained as follows. $\mathrm{Cu}$ atoms have a relatively low bond energy with $\mathrm{Si}, \mathrm{O}$ and $\mathrm{C}$ atoms (Cu-Si: $224 \mathrm{~kJ} / \mathrm{mol}$; Cu-O: $287 \mathrm{~kJ} / \mathrm{mol}, \mathrm{Cu}-\mathrm{C}: 45 \mathrm{~kJ} / \mathrm{mol}$ ), which is much lower than that of Fe atoms (Fe-Si: $310 \mathrm{~kJ} / \mathrm{mol}$, Fe-O: $407 \mathrm{~kJ} / \mathrm{mol}$; Fe-C: $390 \mathrm{~kJ} / \mathrm{mol}) .{ }^{49,50} \mathrm{In}$ addition, $\mathrm{Cu}$ atoms do not preferentially react with $\mathrm{Si}$, $\mathrm{O}$ and $\mathrm{C}$ atoms to form compounds in the amorphous matrix at $800^{\circ} \mathrm{C}$. 

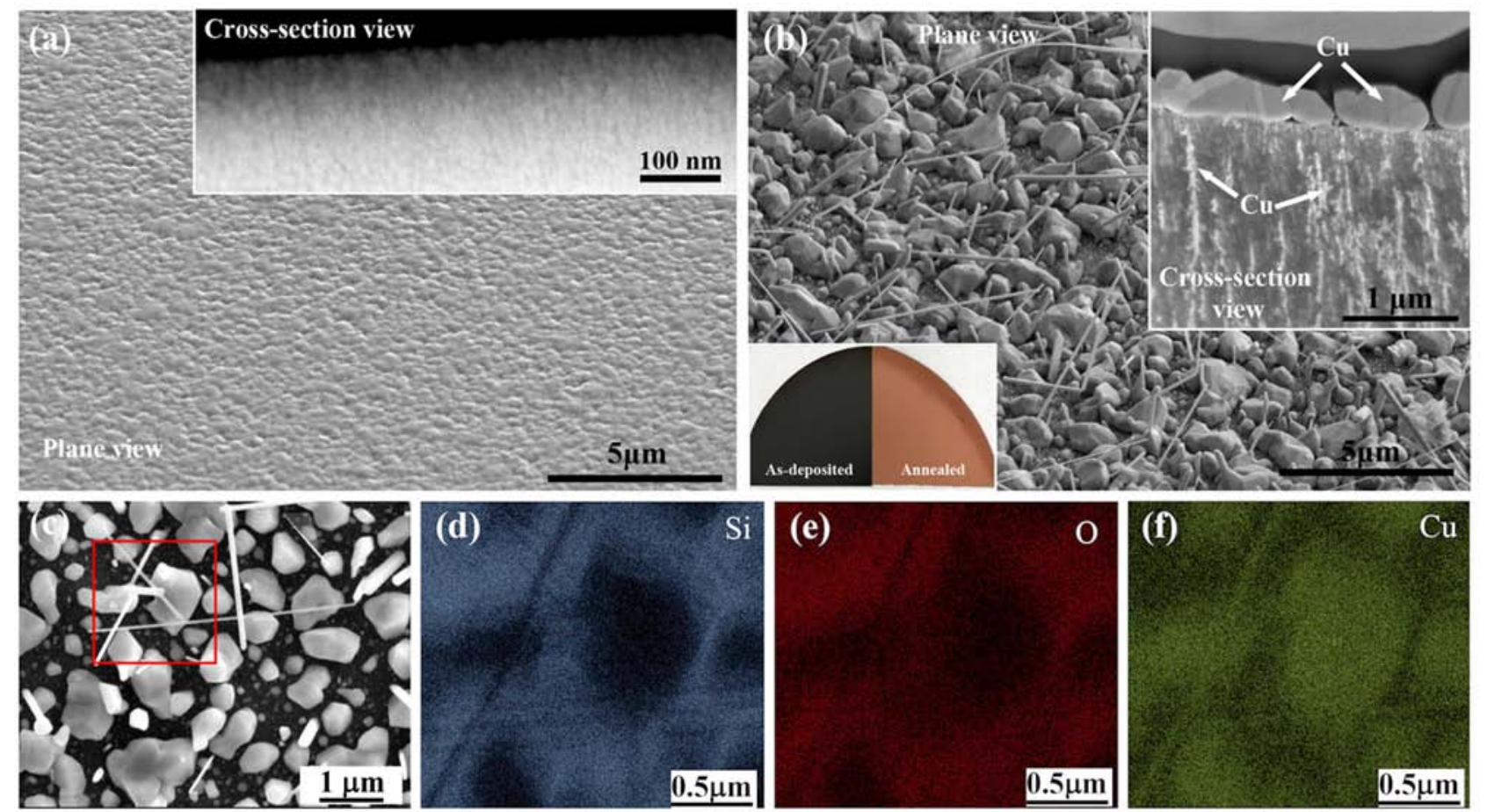

Fig. 3. Microstructures of the Fe-SiOC and $\mathrm{Cu}-\mathrm{SiOC}$ films after annealing at $800^{\circ} \mathrm{C}$ for $1 \mathrm{~h}$. (a) The plan-view SEM image of the annealed Fe-SiOC, with the cross-section view STEM image inset. (b) The plan-view SEM image of the annealed Cu-SiOC, with the cross-section view SEM image inserted at the top-right, and the photograph of the macro-sample before and after annealing inserted at the down-left. (c) The enlarged SEM image of a the annealed Cu-SiOC film, and the (d), (e) and (f) elemental mapping of the outlined area in (c), showing that particles and nanowires are enriched in $\mathrm{Cu}$ but poor in Si and $\mathrm{O}$.

Thus, $\mathrm{Cu}$ atoms in the amorphous matrix are unstable at high temperatures, segregating at voids and diffusing to free surface of the film during annealing. Moreover, the columnar distribution of $\mathrm{Cu}$ in the amorphous matrix provides a rapid diffusion channel for $\mathrm{Cu}$ atoms during annealing. However, Fe atoms are strongly trapped in the amorphous $\mathrm{SIOC}$ matrix because of the strong bond strength and the easy formation of compounds between the $\mathrm{Fe}$ and $\mathrm{Si} / \mathrm{O} / \mathrm{C}$ atoms. Therefore, the $\mathrm{Fe}$ atoms still stay in the amorphous matrix in the form of Fe-rich particles after annealing (inset in Fig. 3a).

The mechanical response of the $\mathrm{Fe}-\mathrm{SiOC}$ and $\mathrm{Cu}-\mathrm{SiOC}$ composites was examined systematically using in situ micro-pillar compression testing inside a SEM (Supplementary Movie S1-S5), as demonstrated in Figs. 4 and 5 . Figure $4 a$ and $d$ shows the representative room-temperature 

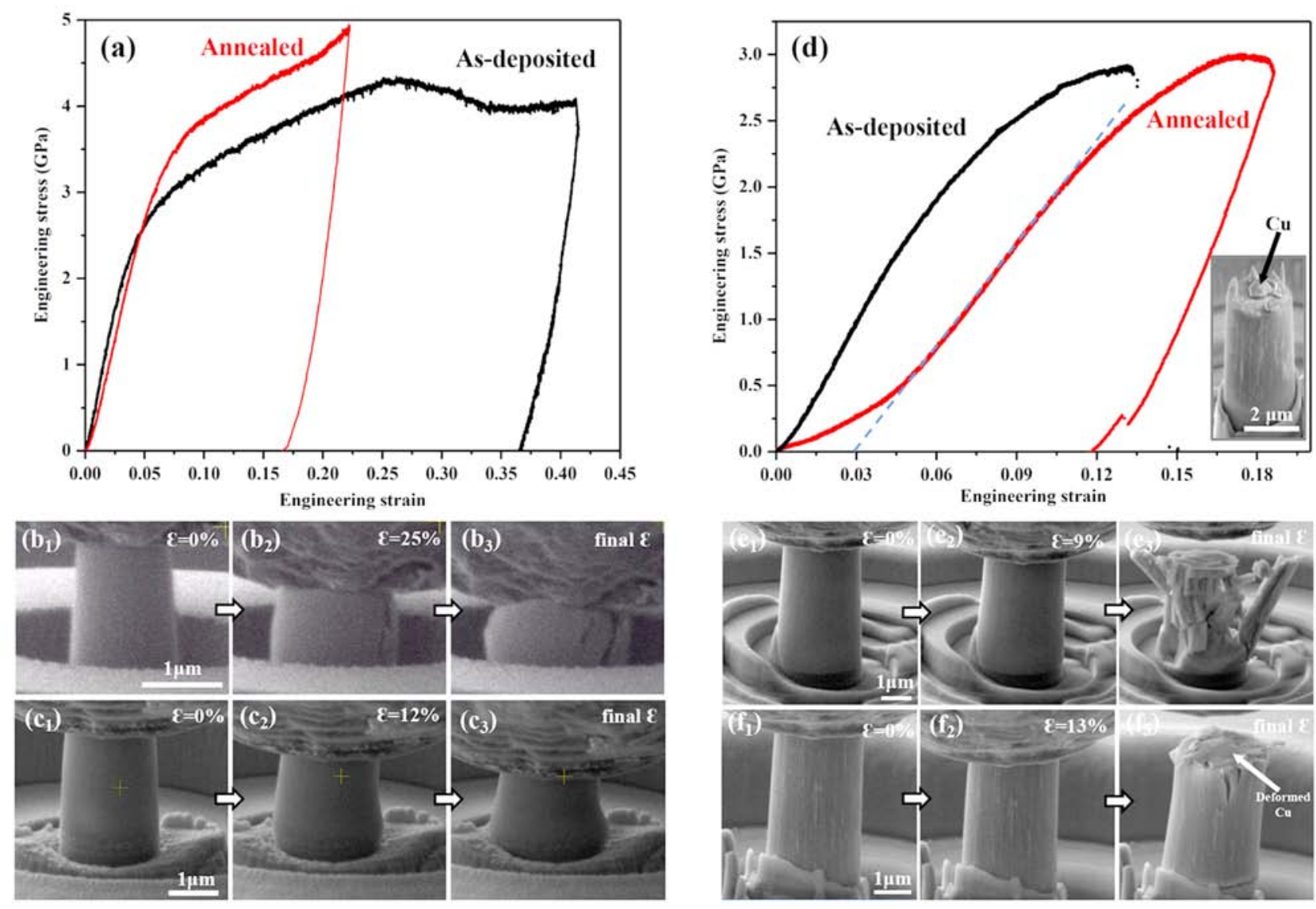

Fig. 4. Mechanical response of the micro-pillars fabricated from $\mathrm{Fe}-\mathrm{SiOC}$ and $\mathrm{Cu}$ $\mathrm{SiOC}$ composites in as-deposited and annealed states. Engineering stress-strain curves of (a) Fe-SiOC and (d) Cu-SiOC composites. The corresponding SEM snapshots captured at different strains (e) during in situ tests for $\left(\mathbf{b}_{\mathbf{1}}-\mathbf{b}_{\mathbf{3}}\right)$ as-deposited Fe-SiOC, $\left(\mathbf{c}_{\mathbf{1}}-\mathbf{c}_{3}\right)$ annealed Fe-SiOC, $\left(\mathbf{e}_{1}-\mathbf{e}_{3}\right)$ as-deposited Cu-SiOC, and $\left(\mathbf{f}_{1}-\mathbf{f}_{3}\right)$ annealed $\mathrm{Cu}$-SiOC.

engineering stress-strain curves of the micro-pillars fabricated from the as-deposited and annealed Fe-SiOC and $\mathrm{Cu}$-SiOC composites. Figure $4 \mathrm{~b}$, $c$, e, and $f$ are the corresponding SEM snapshots captured at different strains (e) during in situ testing. As compared to the brittle-like behavior observed in the as-deposited SiOC, the as-deposited Fe-SiOC composite displays a substantial increase in plasticity and flow strength (Fig. 4a). The uniform compressive strain of the as-deposited Fe-SiOC composite reaches 25\%, and the flow strength exceeds $4 \mathrm{GPa}$. Based on the snapshots taken during in situ micro-compression testing (Fig. $4 b_{1}, b_{2}$ and $b_{3}$ ), we found that the as-deposited Fe-SiOC composite shows a good strainhardening capacity and even a good resistance to crack propagation. 


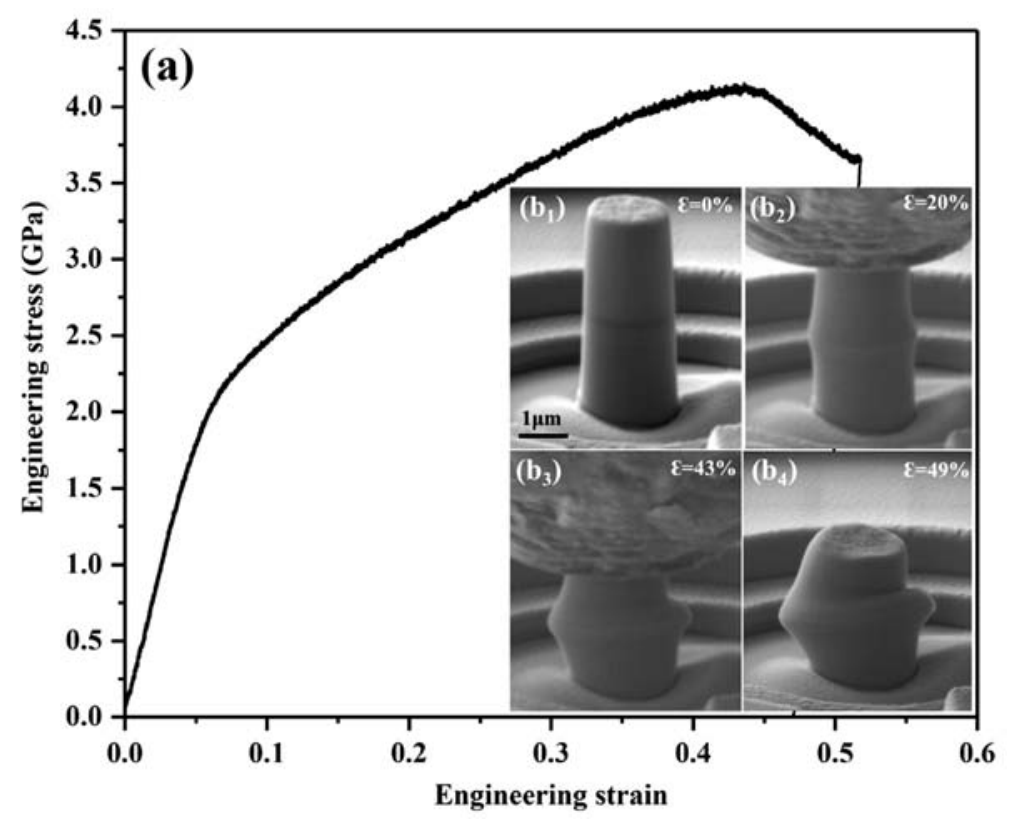

Fig. 5. Mechanical response of the micro-pillars fabricated from Fe-SiOC composited after irradiation to $0.5 \mathrm{dpa}$. (a) Engineering stress-strain curve. $\left(\mathbf{b}_{\mathbf{1}}-\mathbf{b}_{\mathbf{4}}\right)$ The corresponding SEM snapshots captured at different strains (e) during in situ tests.

Annealing further increases the flow strength of the Fe-SiOC composite (Fig. 4a), and the annealed sample exhibits homogeneous plastic deformation associated with a significant strain hardening (Fig. $4 c_{1}, c_{2}$ and $c_{3}$ ). These results indicate that the introduction of amorphous Fe-rich nanoclusters in the amorphous SiOC can enable the design of amorphous ceramics that plastically deform, and even accompanied by homogeneous strain hardening. By contrast, the $\mathrm{Cu}-\mathrm{SiOC}$ composite exhibits a quite different mechanical response. As shown in Fig. 4d, although the as-deposited $\mathrm{Cu}$-SiOC composite exhibits a slight increase in compressive strain before fracture as compared with SiOC film, its flow strength is reduced substantially by about $1.0 \mathrm{GPa}$. Furthermore, when the maximum compressive stress is reached, around $3 \mathrm{GPa}$, the as-deposited $\mathrm{Cu}-\mathrm{SiOC}$ composite displays abrupt comminuted fracture (see Fig. $4 \mathrm{e}_{1}, \mathrm{e}_{2}$ and $\mathrm{e}_{3}$ and Supplementary Movie S3). Annealing does not improve the mechanical properties of the $\mathrm{Cu}-\mathrm{SiOC}$ composite. As shown in Fig. $4 \mathrm{~d}$, the annealed $\mathrm{Cu}-\mathrm{SiOC}$ composite possesses a similar flow strength to the as-deposited $\mathrm{Cu}-\mathrm{SiOC}$, and a slight increase in compressive strain. This increased strain is attributed to the plastic deformation of Cu particles on the surface, which contributes to the initial compressive strain in the annealed 
sample, as indicated in Fig. $4 d$ inset and $f_{3}$. Cracks are also observed in the annealed $\mathrm{Cu}$ - SiOC (Fig. $4 \mathrm{f}_{3}$ ) at the maximum flow stress, which propagates along the columnar structure in the amorphous matrix, also parallel to the loading direction. The catastrophic fracture in both the as-deposited and annealed Cu-SiOC composites suggests that the interfaces between crystalline Cu nano-particles and the amorphous matrix are very weak, and thus act as nucleation sites for cracks. The columnar distribution of $\mathrm{Cu}$ in the amorphous matrix facilitates the rapid propagation of cracks, leading to catastrophic fracture. The above results indicate that introducing $\mathrm{Fe}$ atoms in the amorphous SiOC ceramic matrix enhances the mechanical properties of the amorphous SiOC ceramic.

In addition to high strength, plasticity and thermal stability, the amorphous Fe-SiOC composite also exhibits good irradiation tolerance. After irradiation to $0.5 \mathrm{dpa}$, the Fe-SiOC composite has uniformly distributed nano-sized amorphous Fe-rich clusters in an amorphous matrix, showing no change in microstructure as compared to the as-deposited FeSiOC composite. Figure 5a shows the engineering stress-strain curve of the micro-pillars fabricated from the irradiated Fe-SiOC composite. Figure $5 \mathrm{~b}$ shows the corresponding SEM snapshots captured at different strains (e) during in situ testing. The irradiated Fe-SiOC composite exhibits a high flow strength (exceeding $4 \mathrm{GPa}$ ), high plasticity (compressive strain $>40 \%$ ) and strain hardening. Figure $5 b_{1}, b_{2}, b_{3}$ and $b_{4}$ shows that the pillar is compressed to a barrel-like shape without cracking or fracture, indicating exceptional deformability. These results indicate that the Fe-SiOC composite displays high microstructural and mechanical stability under ion irradiation. The good irradiation tolerance of the present Fe-SiOC composites can be explained as follows. Under irradiation, Fe atoms (associated with Fe-rich clusters in the amorphous SiOC ceramic matrix) are easily displaced compared to elements $\mathrm{Si}, \mathrm{C}$ and $\mathrm{O}$, due to their larger displacement cross-section. More importantly, the displaced Fe atoms can diffuse and reassemble into amorphous Fe-rich clusters after irradiation. In addition, the chemical reaction between metal (Fe) and nonmetal ( $\mathrm{Si}, \mathrm{C}$ and $\mathrm{O}$ ) elements could be activated under irradiation, which leads to the formation of ionic bonds and thus increased strength. This suggests that the amorphous Fe-SiOC ceramic composite, with high strength, plasticity and thermal stability, as well as potential irradiation tolerance, is a highly promising material for advanced nuclear reactors. In our opinion, much more substantial improvements can be achieved if the dimensions, chemical bonds and spatial patterns of Fe-rich clusters in an amorphous ceramic matrix are further optimized. 


\section{Conclusion}

We fabricated two different metal-amorphous ceramic composites-FeSiOC (22 at.\% Fe) and Cu-SiOC (21 at.\% Cu) composites by magnetron sputtering techniques. Iron atoms are preferred to form into uniformly distributed nano-sized Fe-rich amorphous clusters, while copper atoms are tend to grow as non-uniformly distributed nano-crystalline Cu particles, respectively. The Fe-SiOC composite exhibits high strength and plasticity with associated strain hardening, as well as good thermal stability and irradiation tolerance. These exceptional properties can be attributed to the uniformly distributed nano-sized Fe-rich clusters and the strong bond strength between metal Fe and nonmetal Si, O and C. In contrast, the $\mathrm{Cu}-\mathrm{SiOC}$ composite displays a very low plasticity and poor thermal stability, owing to the weak bond strength between metal $\mathrm{Cu}$ and nonmetal $\mathrm{Si}, \mathrm{O}$ and $\mathrm{C}$. These findings suggest that, when designing advanced metal-amorphous ceramic composites, the metal constituents should be selected according to the thermodynamics and bonding energy between metal and non-metal elements in the amorphous ceramics.

Acknowledgments - We acknowledge the partial financial support from the Department of Energy (DOE) Office of Nuclear Energy and Nuclear Energy Enabling Technologies through Award No. DE-NE0008415, and from the Nebraska Public Power District through the Nebraska Center for Energy Sciences Research at the University of Nebraska-Lincoln. The research was performed in part in National Nanotechnology Coordinated Infrastructure and the Nebraska Center for Materials and Nanoscience, which are supported by the National Science Foundation under Award ECCS: 1542182 and the Nebraska Research Initiative. Ion irradiation was performed at the Center for Integrated Nanotechnologies, an Office of Science User Facility operated for the U.S. DOE Office of Science. Los Alamos National Laboratory, an affirmative action equal opportunity employer, is operated by Los Alamos National Security, LLC, for the National Nuclear Security Administration of the U.S. Department of Energy under Contract DE-AC52-06NA25396.

Supplementary Materials (5 movie files) are attached to the archive record for this article.

\section{References}

1. Y. Katoh, Q. Huang, Y.-H. Han, and S. Risbud, Scr. Mater. 143, 126 (2018).

2. T. Allen, J. Busby, M. Meyer, and D. Petti, Mater. Today 13, 14 (2010). 
3. S.J. Zinkle and G. Was, Acta Mater. 61, 735 (2013).

4. P. Yvon and F. Carré, J. Nucl. Mater. 385, 217 (2009).

5. F. Garner, Compr. Nucl. Mater. 4, 33 (2012).

6. J. Gigax, T. Chen, H. Kim, J. Wang, L. Price, E. Aydogan, S.A. Maloy, D. Schreiber, M. Toloczko, and F. Garner, J. Nucl. Mater. 482, 257 (2016).

7. L. Tan, Y. Katoh, A.A.F. Tavassoli, J. Henry, M. Rieth, H. Sakasegawa, H. Tanigawa, and Q. Huang, J. Nucl. Mater. 479, 515 (2016).

8. E. Little and D. Stow, J. Nucl. Mater. 87, 25 (1979).

9. M.-L. Lescoat, J. Ribis, Y. Chen, E. Marquis, E. Bordas, P. Trocellier, Y. Serruys, A. Gentils, O. Kaïtasov, and Y. De Carlan, Acta Mater. 78, 328 (2014).

10. I. Monnet, P. Dubuisson, Y. Serruys, M.-O. Ruault, O. Kal, and B. Jouffrey, J. Nucl. Mater. 335, 311 (2004).

11. A. Certain, S. Kuchibhatla, V. Shutthanandan, D. Hoelzer, and T. Allen, J. Nucl. Mater. 434, 311 (2013).

12. G.R. Odette and D.T. Hoelzer, JOM 62, 84 (2010).

13. A. Misra, M.J. Demkowicz, X. Zhang, and R.G. Hoagland, JOM 59, 62 (2007).

14. X. Zhang, K. Hattar, Y. Chen, L. Shao, J. Li, C. Sun, K. Yu, N. Li, M.L. Taheri, H. Wang, J. Wang, and M. Nastasi, Prog. Mater Sci. 96, 217 (2018).

15. M. Nastasi, Q. Su, L. Price, J.A. Colón Santana, T. Chen, R. Balerio, and L. Shao, J. Nucl. Mater. 461, 200 (2015).

16. Q. Su, B. Cui, M.A. Kirk, and M. Nastasi, Philos. Mag. Lett. 96, 60 (2016).

17. P. Colombo, G. Mera, R. Riedel, and G.D. Sorarù, J. Am. Ceram. Soc. 93, 1805 (2010).

18. Q. Su, S. King, L. Li, T. Wang, J. Gigax, L. Shao, W.A. Lanford, and M. Nastasi, Scr. Mater. 146, 316 (2018).

19. K. Ming, C. Gu, Q. Su, Y. Wang, A. Zare, D.A. Lucca, M. Nastasi, and J. Wang, J. Nucl. Mater. 516, 289 (2019).

20. J.A. Colón Santana, E.E. Mora, L. Price, R. Balerio, L. Shao, and M. Nastasi, Nucl. Instrum. Methods B 350, 6 (2015).

21. Q. Su, S. Inoue, M. Ishimaru, J. Gigax, T. Wang, H. Ding, M.J. Demkowicz, L. Shao, and M. Nastasi, Sci. Rep. 7, 3900 (2017).

22. C.G. Pantano, A.K. Singh, H. Zhang, and J. Sol-Gel, Sci. Technol. 14, 7 (1999).

23. G.D. Sorarù, D. Suttor, and J. Sol-Gel, Sci. Technol. 14, 69 (1999).

24. R. Harshe, C. Balan, and R. Riedel, J. Eur. Ceram. Soc. 24, 3471 (2004).

25. G.D. Sorarù, E. Dallapiccola, and G. D'Andrea, J. Am. Ceram. Soc. 79, 2074 (1996).

26. T. Rouxel, G.-D. Soraru, and J. Vicens, J. Am. Ceram. Soc. 84, 1052 (2001).

27. T. Rouxel, G. Massouras, G.-D. Sorarù, and J. Sol-Gel, Sci. Technol. 14, 87 (1999).

28. G.D. Sorarù, S. Modena, E. Guadagnino, P. Colombo, J. Egan, and C. Pantano, J. Am. Ceram. Soc. 85, 1529 (2002).

29. A. Argon, Acta Metall. 27, 47 (1979).

30. A. Greer, Y. Cheng, and E. Ma, Mater. Sci. Eng. R 74, 71 (2013). 
31. C.A. Schuh, T.C. Hufnagel, and U. Ramamurty, Acta Mater. 55, 4067 (2007).

32. M.M. Trexler and N.N. Thadhani, Prog. Mater Sci. 55, 759 (2010).

33. M. Chen, Annu. Rev. Mater. Res. 38, 445 (2008).

34. W.H. Wang, Prog. Mater Sci. 57, 487 (2012).

35. Y. Cheng and E. Ma, Prog. Mater. Sci. 56, 379 (2011).

36. J. Pan, Q. Chen, L. Liu, and Y. Li, Acta Mater. 59, 5146 (2011).

37. L. Li, E.R. Homer, and C.A. Schuh, Acta Mater. 61, 3347 (2013).

38. J. Qiao, H. Jia, and P.K. Liaw, Mater. Sci. Eng. R 100, 1 (2016).

39. J. Wang, Q. Zhou, S. Shao, and A. Misra, Mater. Res. Lett. 5, 1 (2017).

40. A. Misra, M. Demkowicz, J. Wang, and R. Hoagland, JOM 60, 39 (2008).

41. A. Misra, J. Hirth, and R. Hoagland, Acta Mater. 53, 4817 (2005).

42. Y. Wang, J. Li, A.V. Hamza, and T.W. Barbee, Proc. Natl. Acad. Sci. USA 104, 11155 (2007).

43. M. Chen, A. Inoue, W. Zhang, and T. Sakurai, Phys. Rev. Lett. 96, 245502 (2006).

44. L. Zhu, S. Shi, K. Lu, and J. Lu, Acta Mater. 60, 5762 (2012).

45. T. Fang, W. Li, N. Tao, and K. Lu, Science 331, 1587 (2011).

46. K. Lu, Science 345, 1455 (2014).

47. X. Wu, P. Jiang, L. Chen, F. Yuan, and Y.T. Zhu, Proc. Natl. Acad. Sci. USA 111, 7197 (2014).

48. M. Nastasi, N. Michael, J. Mayer, J.K. Hirvonen, and M. James, Ion-Solid Interactions: Fundamentals and Applications (Cambridge: Cambridge University Press, 1996).

49. T. Rouxel, J. Am. Ceram. Soc. 90, 3019 (2007).

50. Y.-R. Luo, Comprehensive Handbook of Chemical Bond Energies (Boca Raton: CRC Press, 2007). 